\title{
Variation in Nutritional Composition of Australian Mungbean Varieties
}

\author{
Daniel J. Skylas ${ }^{1,2}$, Christopher L. Blanchard ${ }^{2} \&$ Ken J. Quail ${ }^{1}$ \\ ${ }^{1}$ Australian Export Grains Innovation Centre, North Ryde, NSW, Australia \\ ${ }^{2}$ ARC Industrial Transformation Training Centre for Functional Grains, Charles Sturt University, Wagga Wagga, \\ NSW, Australia \\ Correspondence: Daniel J. Skylas, Australian Export Grains Innovation Centre, North Ryde, NSW, Australia. Tel: \\ 61-(0)2-8025-3200. E-mail: daniel.skylas@aegic.org.au
}

Received: February 21, 2017

Accepted: March 20, 2017

Online Published: April 15, 2017

doi:10.5539/jas.v9n5p45

URL: https://doi.org/10.5539/jas.v9n5p45

\begin{abstract}
Australian mungbean production is primarily focused in Central and Southern Queensland and Northern NSW, with around $95 \%$ of the total mungbean crop exported as a commodity to overseas markets. Significant improvement in pulse crops such as mungbean have primarily been achieved from plant breeding approaches focused on increasing yield and disease resistance. Whilst this remains crucial for the ongoing success and production of the crop, further improvements could be achieved through an increased understanding of nutritional variation, varietal performance and the impact of environmental and agronomic factors on overall nutritional quality. In this survey, the primary objective was to evaluate and compare the nutritional composition of three commercial Australian mungbean varieties (Crystal, Satin II and Celera II-AU), grown in different regions in Queensland (Warra and Hermitage sites) and New South Wales (Liverpool Plains and Northern NSW sites). Mungbean varieties were evaluated in terms of visual seed appearance, measuring seed colour and size, prior to comprehensive nutritional evaluation of milled mungbean flours in order to determine the extent of variation between varieties and regions. Moisture, protein, ash, fat, dietary fibre (total, insoluble and soluble fibre), starch and amylose composition, starch pasting properties (RVA profile) and amino acid compositions were evaluated and compared. This survey may potentially lead to a larger scale evaluation in the future, broadening the scope to include other significant Australian pulse crops such as faba bean and chickpea. Ultimately, the information gathered from this survey may assist plant breeders, producers and processors in regard to improving, growing, processing and value-adding Australian mungbean for both domestic and export markets.
\end{abstract}

Keywords: mungbean, variety, nutrition, protein, Australia

\section{Introduction}

The Australian pulse industry plays a crucial role in driving the future sustainability of the Australian grains industry. Pulses provide a range of benefits and are used in cereal crop rotations, breaking cereal disease and weed cycles, fixing atmospheric nitrogen into the soil, consequently, reducing the need for nitrogen fertilisers. These benefits are considered essential for a sustainable and more efficient grains industry in the future. The main pulse crops grown in Australia are chickpea, field pea, lupins, lentils, faba bean and mungbean. Australian mungbean production is primarily focussed in Central and Southern Queensland and Northern New South Wales, with around $95 \%$ of the crop exported to countries such as India, Asia and North America (AEGIC, 2015).

Considerable efforts in plant breeding have primarily focussed on increased yield and disease resistance, which is crucial for the ongoing success and production of the crop. With an increasing understanding of the potential health benefits of pulse consumption in the human diet, there may be opportunities in the future for enhancing nutritional qualities through breeding and the development of new varieties (Nair et al., 2013). Surveying the nutritional qualities and variation resulting from varietal, environmental and agronomic factors would provide valuable information for plant breeders, producers, agronomists and food processors. Identification of varieties or regions with higher protein content or other desirable quality attributes may enable further product differentiation for Australian mungbean in both domestic and export markets. Traditionally, pulse crops have been marketed as a commodity and graded on the basis of appearance, colour, size and purity. There may be opportunities in the future for further value adding to pulse crops by responding to the ever changing food 
processing industry and their requirements for high protein and high fibre functional food ingredients from raw materials. This may be achieved by modifying or expanding pulse quality classification in order to reflect the quality attributes that are sought after by the food processing industry. Shifting the dynamics at play in quality classification may also contribute to increased sustainability by reducing the amount of the crop down graded on the basis of visual appearance and increasing the value of the crop based on nutritional attributes.

Knowledge regarding the variation in nutritional quality of commercial Australian mungbean varieties so far has been limited, even more so, in regard to seasonal and regional variations. This scenario seems to be prevalent in other mungbean producing countries, prompting a recent assessment of the nutritional composition of twenty commercial mungbean varieties grown in China (Shi et al., 2016). The authors reported significant differences in nutritional composition between varieties and also found high levels of resistant starch. Dahiya et al. (2013) also investigated the nutritional composition of selected newly bred and established mungbean varieties grown in India. Further studies comparing mungbean varieties grown in both China (Li et al., 2011) and India (Kaur et al., 2011), focussed on starch physicochemical properties, structure and digestibility, reporting varietal variations that can impact processing quality and end-use applications. Varietal differences in protein content, protein isolates and functional properties have also been investigated (Li et al., 2010; Liu et al., 2015).

In this study, the objective was to survey three commercial Australian mungbean varieties (Crystal, Satin II and Celera II-AU), grown in different regions in QLD (Warra and Hermitage sites) and NSW (Liverpool Plains and Northern NSW sites), in order to determine the extent of nutritional variation. It was not the intention to carry out any detailed genotype-by-environment $(\mathrm{G} \times \mathrm{E})$ study, but rather to develop a better understanding of the nutritional composition of commercial Australian mungbean varieties and how these varieties perform in different regions. Crystal variety was released in 2008 and is large-seeded and shiny green in colour. Crystal is considered the dominant variety produced in Australia and is renown as a more robust and consistent performer in all regions, preferred by cooking and processing markets. Satin II was released in 2008, replacing the Satin variety and is also large-seeded, but with a characteristic dull green colour, preferred by niche markets. Celera II-AU was released in 2014 and is small-seeded and shiny green in colour, preferable for splitting and milling processes (varietal information sourced from Pulse Australia; www.pulseaus.com.au). In this study, seeds from mungbean varieties were initially assessed for visual appearance, size and colour, prior to being milled to flour for nutritional analyses. Energy value, protein, moisture, ash, fat, dietary fibre, starch and amylose composition, starch pasting properties (RVA profile) and amino acid compositions were evaluated and compared. This survey could lead to a larger scale evaluation in the future, potentially including other significant Australian pulse crops such as faba bean and chickpea.

\section{Materials and Methods}

\subsection{Mungbean Seed Material}

Mungbean seed samples were provided by the Department of Agriculture and Fisheries (DAF), Hermitage Research Facility (Warwick, QLD). The mungbean varieties provided for evaluation were Crystal, Satin II and Celera II-AU. These varieties were grown at Warra (Darling Downs region, QLD), Hermitage Research Station (QLD), Liverpool Plains (North-Western NSW) and Northern NSW. Mungbean seed samples were placed over a $2 \mathrm{~mm}$ screen to remove broken seeds and foreign material. Clean and sound seed samples were scanned for visual varietal documentation, then measured for seed colour (Minolta) and seed size, as determined by thousand kernel weight (TKW) using a Numigral seed counter. Mungbean samples were milled to flour using a hammer mill (with $0.5 \mathrm{~mm}$ screen) and measured for flour colour using Minolta.

\subsection{Nutritional Analysis}

All nutritional testing was carried out in duplicate at the Analytical Laboratory based at the Australian Export Grains Innovation Centre (AEGIC) in Sydney. Protein content was determined by the Dumas method using the LECO TruMac protein analyser. Nitrogen determinations were converted to protein (\%) using a 6.25 conversion factor. Ash content was determined by AOAC Official Method 923.03 and AACC Method 08-01.01. Moisture was determined by AOAC Official Method 925.10 and AACC Method 44-15.02. Total, insoluble and soluble dietary fibre (by difference) determinations were carried out according to AOAC Official Method 985.29 and 991.42. Total starch was determined by the Megazyme Starch Assay Kit (AOAC Official Method 996.11 and AACC Method 76-13.0). Resistant starch was determined by the Megazyme Resistant Starch Assay Kit (AOAC Official Method 2002.02 and AACC Method 32-40.01). Starch pasting properties were determined using a Rapid Visco Analyser (Newport scientific RVA Tecmaster) according to AACC Method 76.21.1. 


\subsection{Amino Acid Analysis}

Amino acid (AA) analysis was carried out at the Australian Proteome Analysis Facility (APAF) based at Macquarie University. Protein samples were subjected to $24 \mathrm{~h}$ liquid hydrolysis in $6 \mathrm{M} \mathrm{HCl}$ at $110{ }^{\circ} \mathrm{C}$. During hydrolysis, asparagine is hydrolysed to aspartic acid and glutamine is hydrolysed to glutamic acid. The reported amount of aspartic acid and glutamic acid is the sum of their respective components. Both cysteine and tryptophan are destroyed under these hydrolysis conditions and were analysed separately. Cysteine analysis was carried out using performic acid oxidation followed by $24 \mathrm{~h}$ gas phase hydrolysis at $110^{\circ} \mathrm{C}$. Tryptophan analysis was carried out by $24 \mathrm{~h}$ liquid hydrolysis in $5 \mathrm{M} \mathrm{NaOH}$ at $110^{\circ} \mathrm{C}$. After completion of hydrolysis, all AAs were analysed using the Waters AccQTag Ultra chemistry on a waters Acquity UPLC. Samples were analysed in duplicate and average results were reported.

\section{Results and Discussion}

\subsection{Mungbean Varietal Seed Characteristics}

Representative seed material from Crystal, Satin II and Celera II-AU varieties, produced in the Warra region, is shown in Figure 1 for a visual comparison of relative seed size and colour. Seed weight, measured by TKW, as well as seed and flour colour were measured and reported in Table 1. Mungbean seed colour is an important quality indicator and colour measurements were reported as brightness $\left(\mathrm{L}^{*}\right)$, yellowness $\left(b^{*}\right)$ and red/green colouration $\left(\mathrm{a}^{*}\right)$. Mungbean flour colour was similar between varieties with only slight variations observed. Crystal usually had the largest seeds, while Celera II-AU consistently had the smallest seeds. In terms of seed weight, TKW for Crystal was fairly consistent for Warra, Hermitage and Liverpool Plains, ranging from 62.4 to $66.6 \mathrm{~g} / 1000$ seeds, increasing to $74.4 \mathrm{~g} / 1000$ seeds for the Northern NSW region. TKW for Satin II was consistent for Hermitage, Liverpool Plains and Northern NSW, ranging from 61.1 to $67.7 \mathrm{~g} / 1000$ seeds, increasing to $76.8 \mathrm{~g} / 1000$ seeds for the Warra region. Celera II-AU, a small-seeded variety, ranged from 33.5 to $37 \mathrm{~g} / 1000$ seeds for Warra, Hermitage and Liverpool Plains, reaching $40.7 \mathrm{~g} / 1000$ seeds for Northern NSW.

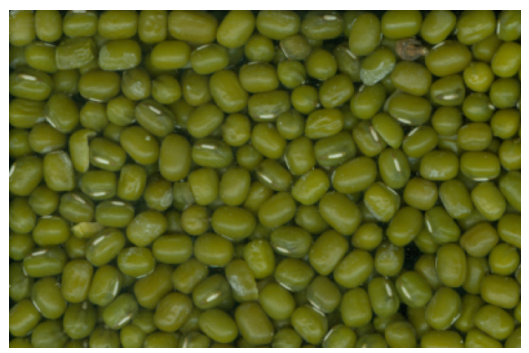

Crystal

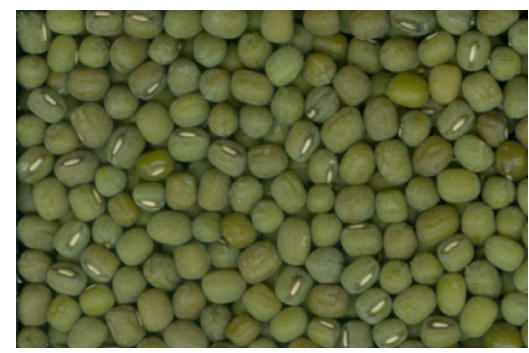

Satin II

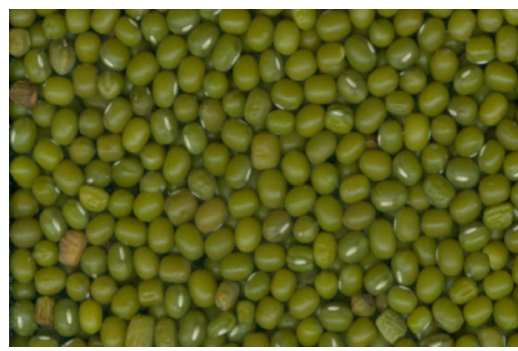

Celera II-AU

Figure 1. Representative seed material for Crystal, Satin II and Celera II-AU mungbean varieties, produced from the Warra region in QLD 
Table 1. Comparison of mungbean varietal seed weight and colour characteristics

\begin{tabular}{|c|c|c|c|c|c|c|c|}
\hline \multirow{2}{*}{ Variety (Region) } & \multirow{2}{*}{ TKW (g/1000) } & \multicolumn{3}{|c|}{ Seed colour } & \multicolumn{3}{|c|}{ Flour colour } \\
\hline & & $\mathrm{L}^{*}$ & $a^{*}$ & $\mathrm{~b}^{*}$ & $\mathrm{~L}^{*}$ & $a^{*}$ & $\mathrm{~b}^{*}$ \\
\hline \multicolumn{8}{|l|}{ Warra } \\
\hline Crystal & 62.4 & $42.8 \pm 0.3$ & $-3.5 \pm 0.1$ & $13.6 \pm 0.5$ & $62.7 \pm 0.0$ & $-1.6 \pm 0.0$ & $9.7 \pm 0.0$ \\
\hline Satin II & 76.8 & $44.9 \pm 0.1$ & $-1.2 \pm 0.0$ & $9.7 \pm 0.1$ & $62.5 \pm 0.2$ & $-0.9 \pm 0.0$ & $9.0 \pm 0.1$ \\
\hline Celera II-AU & 37.0 & $43.1 \pm 0.2$ & $-2.4 \pm 0.0$ & $12.9 \pm 0.1$ & $62.7 \pm 0.0$ & $-1.2 \pm 0.1$ & $9.2 \pm 0.1$ \\
\hline \multicolumn{8}{|l|}{ Hermitage } \\
\hline Crystal & 66.6 & $43.8 \pm 0.1$ & $-3.2 \pm 0.0$ & $14.8 \pm 0.2$ & $63.1 \pm 0.1$ & $-1.5 \pm 0.0$ & $9.6 \pm 0.1$ \\
\hline Satin II & 63.6 & $45.5 \pm 1.3$ & $-2.7 \pm 0.3$ & $11.9 \pm 0.8$ & $63.5 \pm 0.2$ & $-1.4 \pm 0.1$ & $9.5 \pm 0.1$ \\
\hline Celera II-AU & 36.7 & $44.2 \pm 0.1$ & $-3.6 \pm 0.0$ & $14.7 \pm 0.1$ & $61.6 \pm 0.1$ & $-1.5 \pm 0.1$ & $10.6 \pm 0.2$ \\
\hline \multicolumn{8}{|l|}{ Liverpool Plains } \\
\hline Crystal & 65.3 & $45.4 \pm 0.0$ & $-3.0 \pm 0.0$ & $15.3 \pm 0.1$ & $63.7 \pm 0.1$ & $-1.2 \pm 0.0$ & $9.0 \pm 0.0$ \\
\hline Satin II & 61.1 & $47.2 \pm 0.1$ & $-2.7 \pm 0.0$ & $12.9 \pm 0.1$ & $64.3 \pm 0.1$ & $-1.3 \pm 0.1$ & $9.5 \pm 0.1$ \\
\hline Celera II-AU & 33.5 & $45.0 \pm 0.0$ & $-3.4 \pm 0.1$ & $15.2 \pm 0.1$ & $64.0 \pm 0.1$ & $-1.5 \pm 0.1$ & $9.5 \pm 0.3$ \\
\hline \multicolumn{8}{|l|}{ Northern NSW } \\
\hline Crystal & 74.4 & $44.9 \pm 0.1$ & $-2.5 \pm 0.0$ & $14.8 \pm 0.0$ & $64.3 \pm 0.2$ & $-1.3 \pm 0.1$ & $9.6 \pm 0.1$ \\
\hline Satin II & 67.7 & $46.6 \pm 0.3$ & $-2.4 \pm 0.1$ & $12.7 \pm 0.1$ & $64.2 \pm 0.1$ & $-1.3 \pm 0.0$ & $10.2 \pm 0.1$ \\
\hline Celera II-AU & 40.7 & $42.0 \pm 0.1$ & $-1.4 \pm 0.1$ & $10.6 \pm 0.2$ & $63.3 \pm 0.1$ & $-0.9 \pm 0.1$ & $8.4 \pm 0.0$ \\
\hline
\end{tabular}

\subsection{Comparison of Nutritional Content of Australian Mungbean Varieties}

Nutritional proximate composition for all mungbean varieties is reported in Table 2. Energy values were calculated representing the total amount of kilojoules $(\mathrm{kJ})$ from protein, fat, ash and carbohydrate that is released when utilised and digested by the human body. Carbohydrate values comprise starch, dietary fibre and sugars. Sugar content was not directly determined in this study, but starch and dietary fibre composition is reported at a later stage. Energy values were similar for all mungbean varieties, ranging from $1390 \mathrm{~kJ} / 100 \mathrm{~g}$ to $1420 \mathrm{~kJ} / 100 \mathrm{~g}$.

Moisture content was similar for those varieties from the same region, however, the largest variation was reported for mungbean varieties produced in the Warra region, ranging from $9.8 \%$ to $11.5 \%$, for Crystal and Satin II, respectively. Mungbean provides a considerable source of protein and has been previously reported to range from 14.6-32.6\% protein (Dahiya et al., 2015). Protein content reported in Table 2 is on a dry weight basis, with the Crystal variety ranging from $24.1 \%$ (Northern NSW) to $27.5 \%$ (Warra). Satin II exhibited the largest variation in protein content, ranging from $23.6 \%$ (Northern NSW) to $30.1 \%$ (Warra). Celera II-AU ranged from $26.7 \%$ (Liverpool Plains) to $29.9 \%$ (Warra). Based on these results, mungbean grown in the Warra region produced the highest protein content for all three varieties. The lowest protein content for each variety came from mungbean produced in Northern NSW and Liverpool Plains. Fat content showed little variation, ranging from $1.6 \%$ to $2.2 \%$, for Crystal (Warra) and Celera II-AU (Hermitage), respectively. Ash content ranged from $2.7 \%$ to $3.6 \%$, for Crystal (Northern NSW) and Celera II-AU (Liverpool Plains), respectively. Carbohydrate content in mungbean and other pulse crops have formed the basis of numerous studies, comprising mostly of starch (available and resistant), as well as monosaccharides, oligosaccharides and dietary fibres. Total carbohydrate was calculated by difference in Table 2, ranging from $45.5 \%$ to $53.5 \%$, for Celera II-AU (Warra) and Crystal (Northern NSW), respectively. Starch and dietary fibre content is reported in more detail at a later stage. 
Table 2. Nutritional composition of mungbean varieties

\begin{tabular}{|c|c|c|c|c|c|c|}
\hline Variety & $\begin{array}{l}\text { Energy } \\
(\mathrm{kJ} / 100 \mathrm{~g})\end{array}$ & $\begin{array}{l}\text { Moisture } \\
(\%)\end{array}$ & $\begin{array}{l}\text { Protein } \\
\text { Dry basis (\%) }\end{array}$ & Fat $(\%)$ & Ash (\%) & $\begin{array}{l}\text { Carbohydrate } \\
(\%)\end{array}$ \\
\hline \multicolumn{7}{|l|}{ Warra } \\
\hline Crystal & 1400 & 9.8 & 27.5 & 1.6 & 3.3 & 48.9 \\
\hline Satin II & 1400 & 11.5 & 30.1 & 1.9 & 3.1 & 46.5 \\
\hline Celera II-AU & 1390 & 10.6 & 29.9 & 1.9 & 3.3 & 45.5 \\
\hline \multicolumn{7}{|l|}{ Hermitage } \\
\hline Crystal & 1400 & 11.3 & 25.7 & 1.7 & 2.9 & 50.7 \\
\hline Satin II & 1390 & 11.0 & 26.9 & 1.7 & 3.1 & 49.1 \\
\hline Celera II-AU & 1390 & 11.0 & 27.2 & 2.2 & 3.1 & 46.3 \\
\hline \multicolumn{7}{|c|}{ Liverpool Plains } \\
\hline Crystal & 1420 & 10.3 & 25.4 & 1.7 & 3.3 & 52.1 \\
\hline Satin II & 1410 & 10.2 & 26.1 & 1.9 & 3.4 & 49.8 \\
\hline Celera II-AU & 1400 & 9.8 & 26.7 & 2.0 & 3.6 & 47.8 \\
\hline \multicolumn{7}{|l|}{ Northern NSW } \\
\hline Crystal & 1420 & 10.8 & 24.1 & 1.8 & 2.7 & 53.5 \\
\hline Satin II & 1400 & 10.5 & 23.6 & 1.9 & 2.9 & 51.6 \\
\hline Celera II-AU & 1390 & 10.9 & 29.1 & 2.0 & 3.4 & 46.4 \\
\hline
\end{tabular}

\subsection{AA Composition of Mungbean Varieties}

The AA composition of Crystal, Satin II and Celera II-AU grown in different regions is reported in Table 3 (as $\mathrm{mg} / \mathrm{g}$ flour). AAs can generally be classified as being either essential or non-essential in the human diet. Essential AAs cannot be synthesised by the human body, therefore, must be obtained in sufficient quantities from food. Essential AAs include isoleucine, leucine, lysine, methionine, phenylalanine, threonine, tryptophan and valine. Mungbean varieties containing higher proportions of essential AAs would be desirable and beneficial for human consumption. The proportion of essential AAs, relative to total AA content, is reported in Table 3, proving to be highly conserved for these commercial Australian mungbean varieties, ranging from $38.1 \%$ to $38.7 \%$.

The rate limiting AA for all mungbean varieties reported in this study is cysteine, followed by methionine, or in some cases tryptophan. Cysteine and methionine are sulphur-containing AAs, generally rate limiting in pulse flours and protein concentrates. These sulphur-containing AAs show little variation between varieties, ranging from $1.4-1.6 \mathrm{mg} / \mathrm{g}$ flour for cysteine and $2.0-2.7 \mathrm{mg} / \mathrm{g}$ flour for methionine. Low levels of sulphur-containing AAs in mungbean flours can be by compensated for by blending with complementary cereal flours, to obtain a more balanced AA profile. Lysine content, however, is generally higher in pulses compared to cereals, ranging from $13.2 \mathrm{mg} / \mathrm{g}$ to $16.3 \mathrm{mg} / \mathrm{g}$ in this study. The highest lysine content reported for each of the three commercial varieties was produced in the Warra region as a result of higher protein content. Aspartic acid and glutamic acid are reported to be the highest in concentration, however, during amino acid hydrolysis, asparagine is completely hydrolysed to aspartic acid and glutamine is completely hydrolysed to glutamic acid. Values reported for aspartic acid and glutamic acid are the sum of their respective components. 
Table 3. AA composition of commercial Australian mungbean varieties ( $\mathrm{mg} / \mathrm{g}$ flour basis)

\begin{tabular}{|c|c|c|c|c|c|c|c|c|c|c|c|c|c|c|c|c|c|c|c|c|}
\hline Variety & Ala & Arg & $A s p$ & Cys & Glu & Gly & His & Ile & Leu & Lys & Met & Phe & Pro & Ser & Thr & $\operatorname{Trp}$ & $T y r$ & Val & $\begin{array}{l}\text { Total } \\
\text { AA }\end{array}$ & $\begin{array}{l}\text { Essential } \\
\text { AA }(\%)\end{array}$ \\
\hline \multicolumn{21}{|l|}{ Warra } \\
\hline Crystal & 8.0 & 14.6 & 24.0 & 1.5 & 37.1 & 7.0 & 6.5 & 9.5 & 17.0 & 15.2 & 2.3 & 13.2 & 8.8 & 10.5 & 6.9 & 2.6 & 5.0 & 11.0 & 200.7 & 38.7 \\
\hline Satin II & 8.7 & 16.7 & 26.5 & 1.6 & 40.2 & 7.7 & 7.1 & 10.2 & 17.9 & 16.1 & 2.7 & 14.0 & 9.1 & 10.9 & 7.2 & 2.5 & 5.3 & 11.9 & 216.3 & 38.1 \\
\hline Celera II-AU & 8.6 & 16.6 & 26.4 & 1.6 & 40.5 & 7.6 & 7.2 & 10.4 & 18.4 & 16.3 & 2.5 & 14.2 & 9.5 & 11.1 & 7.2 & 2.9 & 5.2 & 12.0 & 218.2 & 38.5 \\
\hline \multicolumn{21}{|l|}{ Hermitage } \\
\hline Crystal & 7.6 & 13.2 & 22.9 & 1.5 & 34.3 & 6.6 & 6.2 & 8.7 & 15.5 & 14.1 & 2.3 & 12.0 & 8.0 & 9.6 & 6.5 & 2.4 & 4.5 & 10.1 & 186.0 & 38.5 \\
\hline Satin II & 7.9 & 13.9 & 24 & 1.5 & 36.1 & 7.4 & 6.4 & 9.2 & 16.2 & 15.1 & 2.3 & 12.6 & 8.3 & 9.9 & 6.7 & 2.3 & 4.8 & 10.7 & 195.3 & 38.5 \\
\hline Celera II-AU & 7.8 & 14.0 & 23.9 & 1.6 & 36.4 & 7.0 & 6.6 & 9.4 & 16.5 & 15.0 & 2.3 & 12.8 & 8.6 & 10.2 & 6.8 & 2.7 & 4.6 & 10.8 & 197.0 & 38.7 \\
\hline \multicolumn{21}{|c|}{ Liverpool Plains } \\
\hline Crystal & 7.6 & 13.2 & 22.5 & 1.4 & 34.3 & 6.6 & 6.3 & 8.8 & 15.5 & 14.0 & 2.3 & 11.9 & 8.0 & 9.5 & 6.4 & 2.3 & 4.5 & 10.2 & 185.3 & 38.5 \\
\hline Satin II & 7.6 & 13.5 & 23.0 & 1.5 & 35.1 & 7.1 & 6.4 & 8.9 & 15.6 & 14.6 & 2.2 & 12.1 & 8.1 & 9.7 & 6.5 & 2.4 & 4.8 & 10.4 & 189.5 & 38.4 \\
\hline Celera II-AU & 7.9 & 13.8 & 23.5 & 1.5 & 35.9 & 7.0 & 6.5 & 9.3 & 16.2 & 14.7 & 2.2 & 12.4 & 8.5 & 9.9 & 6.7 & 2.7 & 4.5 & 10.7 & 193.9 & 38.6 \\
\hline \multicolumn{21}{|c|}{ Northern NSW } \\
\hline Crystal & 7.0 & 12.3 & 21.0 & 1.4 & 32.3 & 6.2 & 6.0 & 8.3 & 14.6 & 13.2 & 2.0 & 11.3 & 7.5 & 8.9 & 6.0 & 2.2 & 4.1 & 9.6 & 173.9 & 38.6 \\
\hline Satin II & 7.0 & 12.0 & 20.7 & 1.5 & 31.6 & 6.6 & 5.9 & 8 & 14.0 & 13.3 & 2.0 & 10.9 & 7.3 & 8.8 & 6.0 & 2.8 & 4.2 & 9.3 & 171.9 & 38.6 \\
\hline Celera II-AU & 8.5 & 15.7 & 25.5 & 1.6 & 39.2 & 7.4 & 6.9 & 9.9 & 17.6 & 15.8 & 2.4 & 13.7 & 9.0 & 10.9 & 7.1 & 2.6 & 4.9 & 11.4 & 210.1 & 38.3 \\
\hline
\end{tabular}

\subsection{Dietary Fibre Composition}

Mungbean and other legumes are a good source of dietary fibre providing a range of reported health benefits (Tharanathan \& Mahadevamma, 2003). Characterisation, functionality and application of dietary fibre in pulses have previously been reviewed (Tosh \& Yada, 2010; Wang \& Toews, 2011). Total dietary fibre (TDF) comprises both insoluble (IDF) and soluble (SDF) fibre components and is reported in Table 4. TDF and the ratio of IDF to SDF can significantly change as a result of primary and secondary processing conditions and is the basis of a further study. Resistant starch is also a form of dietary fibre, however, the standard TDF method used here measures only a portion of the resistant starch content, therefore, was measured directly.

Overall, the TDF content ranged from the lowest at $9.7 \%$ to the highest at $13.2 \%$, for Crystal (Northern NSW) and Celera II-AU (Hermitage), respectively. IDF ranged from 7.4\% to $11.5 \%$, for Crystal (Northern NSW) and Celera II-AU (Hermitage), respectively. SDF was calculated by difference, ranging from $1.7 \%$ to $4.0 \%$, for Celera II-AU, from Hermitage and Liverpool Plains, respectively. Celera II-AU had the highest TDF content in Warra, Hermitage and Liverpool Plains regions and the highest IDF content in all regions, when compared to the other varieties.

Mungbean has previously been reported to contain high levels of resistant starch (Shi et al., 2016), which has been attributed to high amylose content and the structure of amylopectin (Kasemsuwan et al., 1998; Biliaderis et al., 1981). There was considerable variation found in the resistant starch content for the mungbean varieties evaluated in this study. Crystal was the most consistent with resistant starch ranging from $8.7 \%$ (Northern NSW) to $11.8 \%$ (Liverpool Plains). Satin II varied the most, ranging from $2.6 \%$ (Warra) to $16.6 \%$ (Northern NSW). Celera II-AU ranging from $4.7 \%$ (Northern NSW) to $12.2 \%$ (Hermitage) resistant starch. 
Table 4. Dietary fibre composition of mungbean varieties

\begin{tabular}{lcclll}
\hline Variety & TDF (\%) & IDF (\%) & SDF (\%) & IDF/SDF Ratio & Resistant Starch (\%) \\
\hline Warra & & & & & \\
Crystal & 11.6 & 8.0 & 3.6 & 2.2 & 9.0 \\
Satin II & 10.4 & 7.8 & 2.6 & 3.0 & 2.6 \\
Celera II-AU & 12.0 & 9.3 & 2.7 & 3.4 & 8.4 \\
\hdashline Hermitage & & & & & \\
Crystal & 10.6 & 8.3 & 2.3 & 3.6 & 9.7 \\
Satin II & 11.2 & 8.5 & 2.7 & 3.1 & 10.5 \\
Celera II-AU & 13.2 & 11.5 & 1.7 & 6.8 & 12.2 \\
\hline Liverpool Plains & & & & & \\
Crystal & 9.8 & 7.5 & 2.3 & 3.3 & 11.8 \\
Satin II & 11.4 & 7.5 & 3.9 & 1.9 & 14.5 \\
Celera II-AU & 12.7 & 8.7 & 4.0 & 2.2 & 6.9 \\
Northern NSW & & & & & \\
Crystal & 9.7 & 7.4 & 2.3 & 3.2 & 8.7 \\
Satin II & 12.0 & 8.3 & 3.7 & 2.2 & 16.6 \\
Celera II-AU & 11.4 & 8.5 & 2.9 & 2.9 & 4.7 \\
\hline
\end{tabular}

\subsection{Starch Composition and Pasting Properties}

Starch is the most abundant nutrient in cereals and pulses and is accumulated as a store of energy for seed germination. Starch consists of amylose and amylopectin, with the ratio of these two components influencing starch digestibility, pasting properties and end-use applications. Legume starches are characterised by high amylose content, generally found to be greater than $30 \%$ of the total starch composition (Hoover \& Sosulski, 1991). Li et al. (2011) evaluated ten commercial Chinese mungbean cultivars, reporting total starch and amylose content ranging from $54.7-58 \%$ and $40.4-41.8 \%$, respectively. Shi et al. (2016) evaluated twenty commercial Chinese mungbean cultivars, reporting total starch and amylose content ranging from $40.6-48.9 \%$ and $12.5-35.4 \%$, respectively. Total starch and amylose content for mungbean varieties evaluated in this study is reported in Table 5. Total starch content ranged from 38.4\% to $45.1 \%$, for Celera II-AU (Northern NSW) and Satin II (Northern NSW), respectively. Amylose content, as a proportion of total starch, ranged from $30.5 \%$ to $40.7 \%$, for Satin II, produced in both Warra and Liverpool Plains, respectively. Celera II-AU also showed variation in amylose content, but not to the same extent as Satin II, ranging from $31.7 \%$ to $37.1 \%$. Amylose content was more consistent for the Crystal variety, ranging from $33.7 \%$ to $37.1 \%$.

Starch pasting properties were determined by RVA profile and the results are also reported in Table 5. Starch pasting properties reported are peak viscosity (PV), peak time (PT), final viscosity (FV), breakdown (BD), hold viscosity (HV) and set back (SB). PV provides an indication of the water-holding capacity of the mungbean starch mixtures and ranges from 160 to 259 (RVU) between varieties. The PV for Celera II-AU is the lowest from all four regions, ranging from 160 to 188 (RVU). 
Table 5. Total starch, amylose content and pasting properties of mungbean varieties as determined by RVA

\begin{tabular}{lllllllll}
\hline Variety & Starch (\%) & Amylose (\%) & PV (RVU) & PT (min) & FV (RVU) & BD (RVU) & HV (RVU) & SB (RVU) \\
\hline Warra & & & & & & & & \\
Crystal & 40.5 & 33.7 & 242 & 5.1 & 264 & 70 & 172 & 92 \\
Satin II & 39.6 & 30.5 & 181 & 5.0 & 198 & 47 & 134 & 63 \\
Celera II-AU & 38.7 & 31.7 & 163 & 5.0 & 185 & 42 & 121 & 64 \\
\hline Hermitage & & & & & & & \\
Crystal & 43.4 & 34.4 & 236 & 5.1 & 293 & 53 & 183 & 110 \\
Satin II & 41.3 & 33.4 & 236 & 5.0 & 276 & 57 & 178 & 97 \\
Celera II-AU & 39.3 & 36.1 & 170 & 4.8 & 217 & 36 & 134 & 82 \\
- Liverpool Plains & & & & & & & \\
Crystal & 41.9 & 37.1 & 219 & 5.0 & 267 & 55 & 164 & 103 \\
Satin II & 40.8 & 40.7 & 222 & 5.0 & 254 & 59 & 163 & 91 \\
Celera II-AU & 39.7 & 37.7 & 188 & 5.0 & 217 & 53 & 136 & 81 \\
- Northern NSW & & & & & & \\
Crystal & 45.0 & 36.8 & 259 & 5.0 & 291 & 77 & 183 & 109 \\
Satin II & 45.1 & 38.3 & 244 & 4.9 & 268 & 73 & 171 & 97 \\
Celera II-AU & 38.4 & 34.6 & 160 & 5.1 & 213 & 26 & 134 & 78 \\
\hline
\end{tabular}

\section{Conclusion}

The objective of this study was to survey and report the level of nutritional variation between commercial Australian mungbean varieties grown and produced in different regions in QLD and NSW. Information reported in this study may prove to be useful to Australian mungbean producers, plant breeders, agronomists and grain processors in the future. This study has shown that there is some level of variation in the nutritional composition of commercial Australian Mungbean varieties but predominantly these varieties are stable when grown across different regions. Such an example of this variation is the protein content, considered a significant nutritional attribute for mungbean quality, varying considerably for the Satin II variety, ranging from $23.6 \%$ protein content in Northern NSW up to $30.1 \%$ protein in Warra (QLD), an increase of $6.5 \%$ protein on a dry basis. Variations in protein content of this range could be taken advantage of and marketed to the food processing industry as a premium high protein product, attracting premium prices and increasing returns for mungbean producers in that region. Nutritional variations such as increased protein content as well as generally high levels of resistant starch need to be recognised through the mungbean quality classification system and utilised for value-adding purposes and differentiation of premium mungbean products in both domestic and export markets. Further research on mungbean nutrition could include determining variations in mineral content, nutrient digestibility and bioavailability, as well as food processing properties, essential to further strengthening our understanding of mungbean quality and increasing potential value and use as a food source.

\section{Acknowledgements}

I would like to acknowledge the work carried out by the dedicated team at the Analytical Laboratory of the Australian Export Grains Innovation Centre in Sydney. Part of this work was undertaken at APAF with the infrastructure provided by the Australian Government through the National Collaborative Research Infrastructure Strategy (NCRIS).

\section{References}

AEGIC (Australian Export Grains Innovation Centre). (2015). Australian Grain Note: Pulses. Retrieved from http://www.aegic.org.au

Biliaderis, C. G., Grant, D. R., \& Vose, J. R. (1981). Structural characterisation of legume starches. 1. Studies on amylose, amylopectin and beta-limit dextrins. Cereal Chemistry, 58, 496-502.

Dahiya, P. K., Linnemann, A. R., Nout, M. J. R., van Boekel, M. A. J. S., \& Grewal, R. B. (2013). Nutrient composition of selected newly bred and established mungbean varieties. LWT-Food Science and Technology, 54, 249-256. https://doi.org/10.1016/j.lwt.2013.05.017 
Dahiya, P. K., Linnemann, A. R., Van Boekel, M. A. J. S., Khetarpaul, N., Grewal, R. B., \& Nout, M. J. R. (2015). Mungbean: Technological and nutritional potential. Critical Reviews in Food Science and Nutrition, 55, 670-688. https://doi.org/10.1080/10408398.2012.671202

Hoover, R., \& Sosulski, F. (1991). Composition, structure, functionality and chemical modification of legume starches: A Review. Canadian Journal of Physiology and Pharmacology, 69, 79-92. https://doi.org/10.1139/ y91-012

Kasemsuwan, T., Bailey, T., \& Jane, J. (1998). Preparation of clear noodles with mixtures of tapioca and high-amylose starches. Carbohydrate Polymers, 32, 301-312. https://doi.org/10.1016/S0144-8617(97) 00256-7

Kaur, M., Sandhu, K. S., Singh, N., \& Lim, S.-T. (2011). Amylose content, molecular structure, physiochemical properties and in vitro digestibility of starches from different mung bean (Vigna radiata L.) cultivars. Starch/Stärke, 63, 709-716. https://doi.org/10.1002/star.201100053

Li, W., Shu, C., Yan, S., \& Shen, Q. (2010). Characteristics of sixteen mungbean cultivars and their protein isolates. International Journal of Food Science and Technology, 45, 1205-1211. https://doi.org/10.1111/ j.1365-2621.2010.02259.x

Li, W., Shu, C., Zhang, P., \& Shen, Q. (2011). Properties of starch separated from ten mung bean varieties and seeds processing characteristics. Food and Bioprocess Technology, 4, 814-821. https://doi.org/10.1007/ s11947-010-0421-6

Liu, H., Liu, H., Yan, L., Cheng, X., \& Kang, Y. (2015). Functional properties of 8S globulin fractions from 15 mungbean (Vigna radiata (L.) Wilczek) cultivars. International Journal of Food Science and Technology, 50, 1206-1214. https://doi.org/10.1111/ijfs.12761

Nair, R.M., Yang, R-Y., Easdown, W.J., Thavarajah, D., Thavarajah, P., d'A Hughes, J., \& Keatinge, J.D.H. (2013). Biofortification of mungbean (Vigna radiata) as a whole food to enhance human health. Journal of the Science of Food and Agriculture, 93, 1805-1813. https://doi.org/10.1002/jsfa.6110

Pulse Australia. (n.d.). Retrieved from http://www.pulseaus.com.au

Shi, Z., Yao, Y., Zhu, Y., \& Ren, G. (2016). Nutritional composition and antioxidant activity of twenty mungbean cultivars in China. The Crop Journal, 4, 398-406. https://doi.org/10.1016/j.cj.2016.06.011

Tharanathan, R. N., \& Mahadevamma, S. (2003). Grain legumes-a boon to human nutrition. Trends in Food Science \& Technology, 14, 507-518. https://doi.org/10.1016/j.tifs.2003.07.002

Tosh, S. M., \& Yada, S. (2010). Dietary fibres in pulse seeds and fractions: Characterisation, functional attributes and applications. Food Research International, 43, 450-460. https://doi.org/10.1016/j.foodres.2009.09.005

Wang, N., \& Toews, R. (2011). Certain physicochemical and functional properties of fibre fractions from pulses. Food Research International, 44, 2515-252. https://doi.org/10.1016/j.foodres.2011.03.012

\section{Copyrights}

Copyright for this article is retained by the author(s), with first publication rights granted to the journal.

This is an open-access article distributed under the terms and conditions of the Creative Commons Attribution license (http://creativecommons.org/licenses/by/4.0/). 